\title{
Depletion of plankton in a raft culture of Mytilus galloprovincialis in Ría de Vigo, NW Spain. I. Phytoplankton
}

\author{
Jens Kjerulf Petersen ${ }^{1, *}$, Torkel Gissel Nielsen ${ }^{1}$, Luca van Duren ${ }^{2,3}$, Marie Maar $^{1}$ \\ ${ }^{1}$ National Environmental Research Institute, University of Aarhus, Frederiksborgvej 399, PO Box 358, 4000 Roskilde, Denmark \\ ${ }^{2}$ Netherlands Institute of Ecology, Centre for Estuarine and Marine Ecology, PO Box 140, 4400 AC Yerseke, The Netherlands \\ ${ }^{3}$ Present address: DELTARES, Rotterdamseweg 185, PO Box 177, 2600 MH Delft, The Netherlands
}

\begin{abstract}
Food depletion in mussel cultivation has been rarely studied and seldom demonstrated. In this study, concentrations of phytoplankton in and around a blue mussel Mytilus galloprovincialis raft culture unit in the Ría de Vigo were measured during a 2 wk study period in July 2004. Flow direction and current speed were measured using an Aanderaa current meter and fine-scale Acoustic Doppler Velcimeter probes at different positions in the raft. Flow speeds were reduced compared to outside the raft, but a clear tidal signal and significant flow velocities could still be observed inside the raft. At the upstream corners of the raft, a zone of high turbulence but reduced advection was observed. Concentrations of chlorophyll a ( $\mathrm{chl} \mathrm{a}$ ) were measured on 3 different spatial scales. On a macro-scale, fluorescence profiles were taken inside and outside the raft on several occasions and there was depletion of chlorophyll inside the raft corresponding to $~ 80 \%$ of the outside concentration, whereas there was no depletion below the ropes. On a meso-scale, from just upstream to just downstream of the raft, fluorescence profiles, as well as water samples, at several depths revealed similar depletion, however, with larger depletion of size-fractionated chl $a>2 \mu \mathrm{m}$. On a micro-scale, water was sampled within $20 \mathrm{~cm}$ of the ropes using siphon mimics. In the middle of the raft, concentration profiles towards the mussel ropes could be observed at 2 depths, whereas less clear profiles were observed on the turbulent upstream corner. The present study documents food depletion in a mussel culture and emphasizes the importance of physical forcing and phytoplankton composition for food availability.
\end{abstract}

KEY WORDS: Depletion $\cdot$ Mussels $\cdot$ Phytoplankton $\cdot$ Raft culture $\cdot$ Scales $\cdot$ Hydrodynamics

\section{INTRODUCTION}

Mussel cultivation is an extensive form of aquaculture, which is entirely dependent on natural resources for feeding and recruitment. Mussel cultivation can take place in benthic cultures, where mussels are placed on the seabed at convenient sites. It can also take place in long-line culture units, where mussels hang suspended from artificial structures such as rafts. In the former situation, mussels can deplete the lower water layers and they depend on horizontal advection and vertical mixing to transport material from the surface to the bed (Petersen 2004). In the latter situation, mussels have direct access to the whole extent of the water column that is spanned by the mussel ropes. In this latter case, they depend mostly on advection to access suspended plankton. Mussel cultivation has increased dramatically since the middle of last century (Smaal 2002) and has gained increasing international importance (Gibbs 2004).

Since mussel cultivation depends on a natural, external supply of food (primarily phytoplankton) there is a risk that production may fail or decrease if the natural food resources are depleted. For individual mussel farmers it is therefore important that the culture sites are optimally exploited. By increasing the mussel stock 
in the allotted culture sites, there is a risk that the carrying capacity of the site may be exceeded and production will be reduced to local overgrazing. There are few reports on actual depletion of seston within culture units (Perez Camacho et al. 1991, Heasman et al. 1998, Strohmeier et al. 2005), and some have questioned whether depletion can actually be observed (Ogilvie et al. 2000). Depletion will depend not only on the stocking density of the mussels, but will also depend on the nutrient load and physical forcing (Pilditch et al. 2001). Thus, in a nutrient-rich system with high current speeds or wind-driven mixing, depletion will be difficult to detect, and generally mussels can be stocked densely. However, for practical reasons, mussel cultivation often takes place in protected areas with low physical forcing, and depletion may therefore occur in such areas, causing a lower production or individual growth rate of mussels (Strohmeier et al. 2005). However, little is known about the degree of depletion and on what scales depletion can be detected in mussel cultivation rafts.

In the present paper we report measurements of depletion of phytoplankton on different scales using different methods inside and around a longline culture unit for production of blue mussels Mytilus galloprovincialis. Our hypotheses were: (1) that phytoplankton depletion takes place on different scales in mussel culture units, (2) that depletion will be minimal in upstream parts of a culture unit and maximal at the downstream end, and

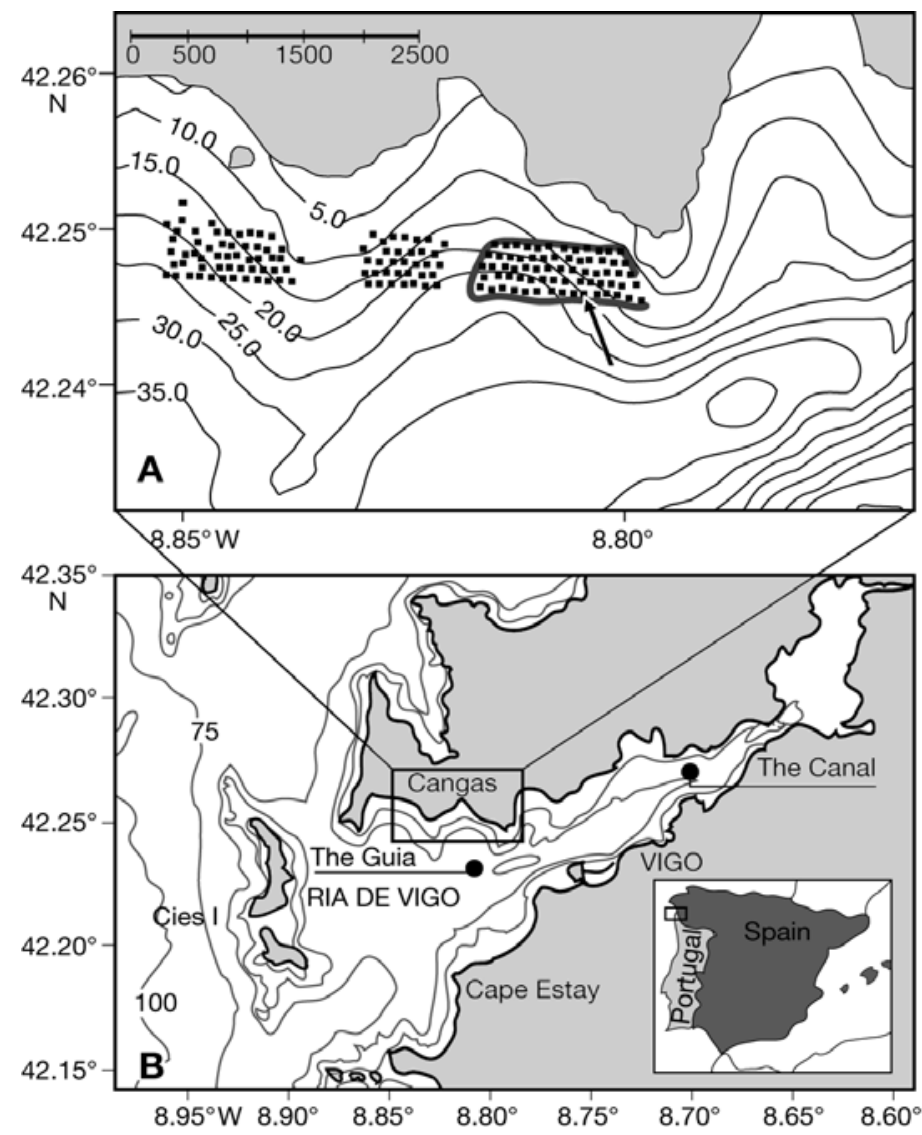

Fig. 1. Map of: (A) the position of the rafts ( - ) and (B) the Ría de Vigo in NW Spain. The studied raft is sixth from the right in the marked polygon in Panel A (black arrow). Units on the scale bar in Panel A are metres

(3) that depletion is dependent on current speed.

We chose Ría de Vigo, NW Spain, as the study area, since it hosts many culture units and constitutes, together with the other Galician rías, one of the most important areas for mussel production in the world (Perez Camacho et al. 1991). The measurements of phytoplankton depletion are linked directly to hydrodynamic parameters measured in the same unit at the same time, allowing direct coupling of physical and biological processes. In the companion paper by Maar et al. (2008, this issue), the depletion of zooplankton within a culture unit and more detailed budget calculations for groups of rafts are demonstrated and discussed.

\section{MATERIALS AND METHODS}

Study site. A raft culture unit situated in the Ría de Vigo (Fig. 1) was used as study site. The raft studied was a standard Spanish unit (Perez Camacho et al. 1991) consisting of a $27 \times 20 \mathrm{~m}$ wooden raft equipped with 551 ropes of 12 to $14 \mathrm{~m}$ each, holding blue mussels Mytilus galloprovincialis of different sizes and at an estimated density of 750 ind. $\mathrm{m}^{-3}$ corresponding to a biomass of $15 \mathrm{~kg} \mathrm{~m}^{-1}$ rope (Perez Camacho et al 1991). Size and number of mussels on a raft varies with season and between the ropes on the raft, but generally size ranges between 20 and $60 \mathrm{~mm}$ (Babarro et al. 2000). The ropes were unevenly spaced, with a larger distance between ropes holding larger mussels. The raft was located in a farm of 68 rafts arranged in a polygon on the northern shore of the Ría de Vigo, close to the village of Cangas (Fig. 1B). Approximate depth of the site was $25 \mathrm{~m}$. The tidal elevation in the area is around $2.5 \mathrm{~m}$, and current velocities outside the raft are in the range of 0.1 to $0.2 \mathrm{~m} \mathrm{~s}^{-1}$ (Riethmüller et al. 2006). Ingoing currents were deflected in the direction of the isobaths, whereas outgoing current direction was highly variable within and around the mussel raft. Intensive and detailed studies were carried out during a study period from 19 to 28 July 2004.

This mussel production area is known to be extremely productive due to predominant upwelling conditions from April to September stimulating phytoplankton production and supporting the high production of blue mussels (Navarro et al. 1991). During the rest of the year, downwelling conditions prevail. Dur- 
ing the study period, water column conditions were influenced by a relaxation between the summer upwelling events and characterised by stratification and low phytoplankton concentrations (Arbones et al. 2008). Inside the ría, wind speeds were $<5 \mathrm{~m} \mathrm{~s}^{-1}$ most of the time during the study period. It is important to note that the average conditions during the study period are not quite representative of the average conditions during summer in most years.

Physics. A current meter (Aanderaa RCM9) equipped with sensors for pressure, temperature, salinity, and current speed and direction was submerged from the centre of the raft at $2 \mathrm{~m}$ depth and sampled mean values with $10 \mathrm{~min}$ intervals. A thermistor string with Ebro thermo-loggers was deployed to sample at 6 depths (surface, 3, 6, 9, 12 and $15 \mathrm{~m}$ ). Additionally, 4 Acoustic Doppler Velocimeters (ADVs) were positioned at different locations on the raft at 3 to $4 \mathrm{~m}$ depth (Fig. 2). A self-contained ADV system, the 'Vector' (Nortek), was placed at the centre of the raft close to a mussel rope (approx. $10 \mathrm{~cm}$ ). This system was programmed to record bursts of 8192 samples at $32 \mathrm{~Hz}$. The first $2 \mathrm{~d}$, this system recorded at 15 min intervals; during the subsequent days, it was set to record at 40 min intervals. In addition to the self-contained ADV, a linked set of 3 Sontek ADVs were operated from a laptop on the raft. Probe 1 was placed lateral to a rope with respect to the main flow, near the corner of the raft, a few ropes from the edge (approx. $6 \mathrm{~cm}$ from the rope). Probes 2 and 3 were placed on the side of the raft, 1 to $1.5 \mathrm{~m}$ from the raft's edge, sampling, respectively, between mussel ropes at a distance of $>50 \mathrm{~cm}$ from any rope (Probe 2) and very close (approx. $6 \mathrm{~cm}$ ) to a mussel rope (Probe 3 ). The length of cable be-

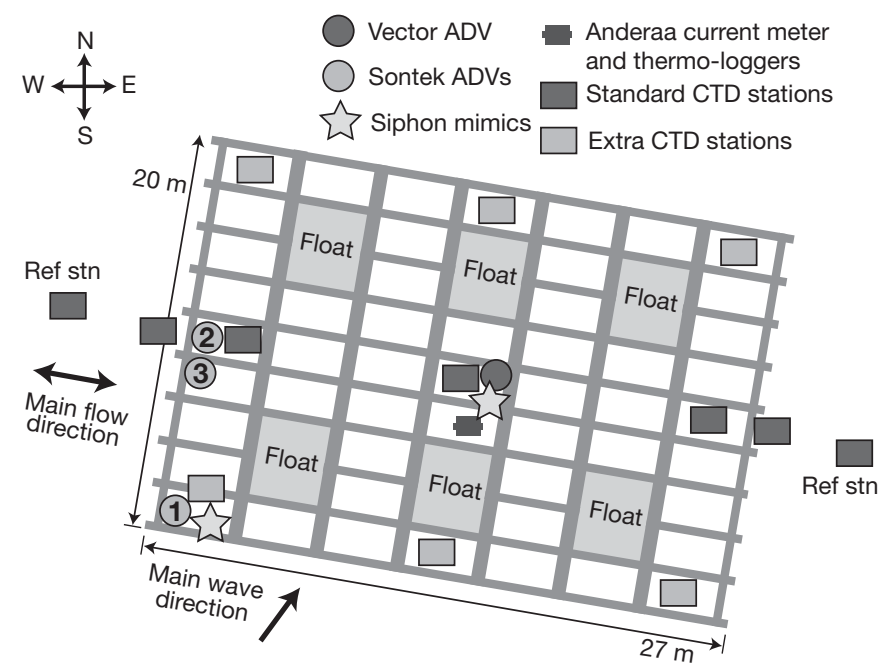

Fig. 2. Map of the raft with sampling positions. The reference stations (Ref stn) were located approximately $30 \mathrm{~m}$ from the raft in upstream and downstream directions (not to scale in the figure) tween the probes largely dictated the relative placement of these 3 probes. All Sontek ADVs sampled at $25 \mathrm{~Hz}$. This set of ADV probes was also set to record bursts of a minimum of 8192 samples. All ADVs were mounted on frames that were attached to the raft. All probes were deployed at a depth of $4 \mathrm{~m}$. The 3 probes that were very close to a rope (the Vector, Probe 1 and Probe 3) were positioned laterally to the ropes with respect to the main flow, i.e. they never were set to measure in the wake of a rope. The $\mathrm{x}$-beams were positioned parallel to the main flow through the raft (i.e. $120^{\circ}$ from north). The ADV frames had a ringshaped guard around the ADV to prevent damage to the probe sensors during deployment. As the measuring volume of an ADV is located underneath the probe (15 $\mathrm{cm}$ for the Vector and $5 \mathrm{~cm}$ for the Sontek system), these guards did not interfere with the measurements.

From each burst, average velocities as well as turbulence characteristics were calculated. Turbulent kinetic energy (TKE) was calculated as:

$$
\mathrm{TKE}=0.5\left({\overline{u^{\prime}}}^{2}+{\overline{v^{\prime}}}^{2}+{\overline{w^{\prime}}}^{2}\right)
$$

with $u^{\prime}, v^{\prime}$ and $w^{\prime}$ being the fluctuating components of the velocities in $x, y$ and $z$. The $x$ direction was aligned with the main flow direction through the raft. An ADV works on the basis of detecting the backscatter signal from suspended particles. There is a linear relationship between the amplitude of the backscatter signal and the particle concentration (Voulgaris \& Meyers 2004). The signal is strongly influenced by the particle composition, in particular the fraction of inorganic material in the particles. However, since flow rates in the raft are rather low and the measurements were taken far away from the influence of the bed, this was assumed not to vary too much. In all ADV measurements, the amplitude of the ADV signal was corrected with the 'signal-to-noise-ratio'. For each burst an average 'corrected amplitude' value was calculated. The Vector and Probe 1 were both located close to a mussel rope where siphon mimic measurements were also taken. This allowed us to convert the amplitude of the backscatter into chlorophyll a (chl a) concentrations, by calibrating the backscatter signal with simultaneous samples from the siphon mimics (see 'Materials and methods-Siphon mimics').

During the study period, a standard program consisting of CTD-casts (ME-profiler from Meerestechnik) measuring temperature, salinity and fluorescence was carried out as synoptically as possible, starting 20 to $30 \mathrm{~m}$ upstream of the raft (reference station), then in front of and behind the leading edge, in the centre, just in front of and behind the trailing edge and 20 to $30 \mathrm{~m}$ downstream of the raft (Fig. 2; standard CTD station). Sampling was performed on 12 occasions during the 
study period according to the tidal cycle of incoming oceanic water or outgoing estuarine water, and 2 of these occasions (22 and 28 July) were detailed for horizontal and vertical spatial resolution of fluorescence within the raft (Fig. 2; extra CTD stations). Depletion of phytoplankton was defined as the proportion of fluorescence in comparison with a reference station $(100 \%)$ that was 20 to $30 \mathrm{~m}$ upstream of the raft (macro-scale), just in front of the leading edge of the raft (meso-scale), or between ropes (micro-scale).

Size-fractionated chl $\mathbf{a}$. Water for estimation of chl a was sampled at 3 depths $(3,9$ and $18 \mathrm{~m})$ using 51 Niskin bottles at selected stations, i.e. the standard program for CTD-casts: upstream, just in front of the raft; at the centre of the unit; at the trailing edge; and 2 to $3 \mathrm{~m}$ downstream of the raft. Additional samples for estimation of total chl a concentrations were taken at 2 depths in the nearby canal also hosting mussel farms and in the open part of the Guia not influenced by mussel farms (Fig. 1). Water samples were analysed for size-fractionated chl a $(<2,2$ to 20,20 to 200 and $>200 \mu \mathrm{m}$ ) on $100 \mathrm{ml}$ triplicate sub-samples filtered onto Whatman G/FF, 2, 20 and $200 \mu$ m filters. The filters were extracted in $96 \%$ ethanol and analysed on a Turner 770 fluorometer, calibrated against a chl a standard, before and after acidification (Yentsch \& Menzel 1963).

Siphon mimics. To resolve depletion patterns at the near-rope (micro) scale, the 'siphon mimic' technique was applied on 4 occasions (21, 23, 24 and 27 July) in the boundary layer surrounding 2 mussel ropes, 1 located at the corner and 1 in the middle of the raft. Both ropes fitted with siphon mimics were located immediately adjacent to ropes with ADVs (Fig. 2). Black plastic tubing (inner diameter $=0.3 \mathrm{~cm}$ ) was attached to a stick and protruded $0.1,3,10$ and $20 \mathrm{~cm}$ from the surface of the ropes. Sticks were mounted on the mussel rope at depths of 3 and $9 \mathrm{~m}$, using plastic cable ties assuring that the surface of the stick was more or less flush with the surface of the clump of mussels. Water was pumped to the surface using a peristaltic pump with a pumping rate of $4.8 \mathrm{l} \mathrm{h}^{-1}$, corresponding to the pumping rate of a 40 to $50 \mathrm{~mm}$ mussel (Riisgård 2001). Sampling of 3 replicates took place within 20 to $30 \mathrm{~min}$, simultaneously at 2 depths at each locality (corner and middle). Water samples (3 replicates) were pre-filtered on an $80 \mu \mathrm{m}$ screen in order to avoid faecal pellets in the sample and were analysed for chl a as described above, but without size fractionation. Pre-filtering was necessary for siphon mimic sampling due to low sampling volume and the close proximity to the mussels.

Depletion model. In order to test if the observed depletion rates were consistent with mussel clearance rates from the literature, we applied a 1-dimensional (1D) depletion model. The model describes horizontal advection and consumption of food by mussels in the surface layer, where vertical mixing prevents a vertical gradient of food concentration (Bacher et al. 2003):

$$
\partial t=-\mathrm{u} \frac{\mathrm{d} C}{\mathrm{~d} x}+C(x, t) \times N \times \mathrm{CR}
$$

where $\mathrm{u}\left(\mathrm{m} \mathrm{s}^{-1}\right)$ is the current speed, $C$ is food concentration, $x(=27 \mathrm{~m})$ is the distance along the main current direction, $N$ (ind. $\mathrm{m}^{-3}$ ) is the abundance of mussels and CR $\left(\mathrm{m}^{3}\right.$ ind. $\left.{ }^{-1} \mathrm{~d}^{-1}\right)$ is the individual clearance rate. Eq. (2) can be solved analytically assuming steady state conditions (e.g. $\partial \mathrm{t}=0)$, and CR can then be estimated as:

$$
\mathrm{CR}=\frac{-\ln \left[\frac{C_{X}}{C_{0}}\right] \times \mathrm{u}}{x \times N}
$$

where we have measurements of the upstream, $C_{0}$, and downstream, $C_{x}$, concentrations of food ( $\mathrm{chl} a$ ) at the distance $x=27 \mathrm{~m}$, current speed, and mussel abundance $\mathrm{N}=750$ ind $\mathrm{m}^{-3}$. Average chl a concentration could be estimated as:

$$
\bar{C}=\frac{C_{0}-C_{x}}{\ln \frac{C_{0}}{C_{X}}}
$$

Ingestion rate of phytoplankton was then calculated as the CR multiplied by the average chl a concentrations converted to carbon biomass $\left(\mathrm{mg} \mathrm{C} \mathrm{m}^{-3}\right)$ using a C:chl a ratio of 58 (Cermeño et al 2006). For additional budget calculations we refer to the companion paper by Maar et al. (2008).

\section{RESULTS}

\section{Physical properties}

The water column was stratified during the study period. Temperature ranged from $13^{\circ} \mathrm{C}$ at $15 \mathrm{~m}$ depth to $21^{\circ} \mathrm{C}$ at the surface. Salinity ranged between 34.8 and 35.5 during the study period (data not shown). From the daily CTD casts, 2 or 3 separate layers within the upper 13 to $14 \mathrm{~m}$ of the water column could be identified and the depth extension of each layer varied between days. This stratification was confirmed by the temperature measurements. Current speeds inside the raft were low and varied from $<0.01$ to just above $0.08 \mathrm{~m} \mathrm{~s}^{-1}$, with an average $( \pm \mathrm{SD})$ velocity during the study period of 0.019 $\pm 0.012 \mathrm{~m} \mathrm{~s}^{-1}$. Current direction was dominated by the tide and highly bi-directional (Fig. 3B). The ADVs measured velocities of roughly the same order of magnitude as the current metre. The Vector gave an average $( \pm \mathrm{SE})$ speed of $0.020 \pm 0.005$, with maximum speeds at incoming and outgoing tides of $\sim 0.06$ and $\sim 0.05 \mathrm{~m} \mathrm{~s}^{-1}$, respec- 

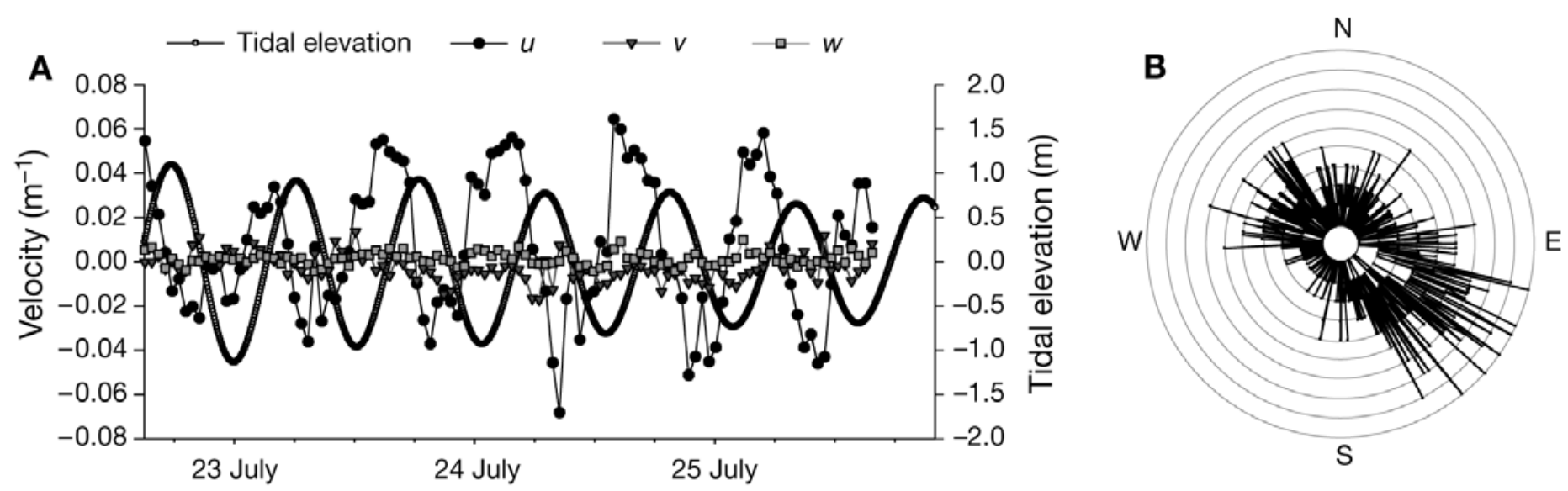

Fig. 3. (A) Link between tidal elevation and current flow at the centre of the raft. $u$ : along raft flow; $v$ : across raft flow velocity; $W$ : vertical velocity. (B) Frequency plot of measured current direction during the study period

tively (Fig. 3A); Probes 2 and 3 also showed a clear tidal signal, with maximum speeds around $0.07 \mathrm{~m} \mathrm{~s}^{-1}$ (Fig. 4A, for clarity this figure only shows a short time sequence, but this pattern was consistent over time). During flood tide, higher velocities were reached than during ebb tide. Average velocity magnitudes were similar: they were higher between mussel ropes at Probe 2 than near a mussel rope at Probe 3 during flood tide (Probe 2: $0.030 \pm 0.016 \mathrm{~m} \mathrm{~s}^{-1}$; Probe 3: $0.029 \pm$ $0.015 \mathrm{~m} \mathrm{~s}^{-1}$ ). The same was true during ebb tide (Probe 2: $0.016 \pm 0.008 \mathrm{~m} \mathrm{~s}^{-1}$; Probe 3: $0.021 \pm$ $0.011 \mathrm{~m} \mathrm{~s}^{-1}$ ). Peak velocities at flood tide ranged around $0.055 \mathrm{~m} \mathrm{~s}^{-1}$ at Probe 2 between the ropes and $0.053 \mathrm{~m} \mathrm{~s}^{-1}$ at Probe 3 close to the rope. There were therefore no discernable effects that could be attributed to velocity boundary layer effects at these distances from the ropes. At the rope on the corner (Probe 1), the tidal signal was much less pronounced. Advection in this area was very low, and Probe 1 had consistently lower flow velocities (flood: $0.012 \mathrm{~m} \mathrm{~s}^{-1}$; ebb: $0.010 \mathrm{~m} \mathrm{~s}^{-1}$; peak velocities rarely exceeding $0.02 \mathrm{~m} \mathrm{~s}^{-1}$ ) than the other 2 probes. Levels of TKE were of a similar order of magnitude between most of the measurements except at Probe 1 (Fig. 4B), where, despite the low velocities, levels of TKE were generally high. This pattern results in much higher turbulence intensities (here: TKE normalised with the square of the velocity magnitude) around Probe 1 in comparison to other locations, apart from the period around the turn of the tide, when flow is near 0 everywhere (Fig. 4C). Diversion of flow around and below the raft apparently creates stable local vortices at the corners of the raft. In these areas there is considerable random motion, but little lateral exchange of water. It is debatable
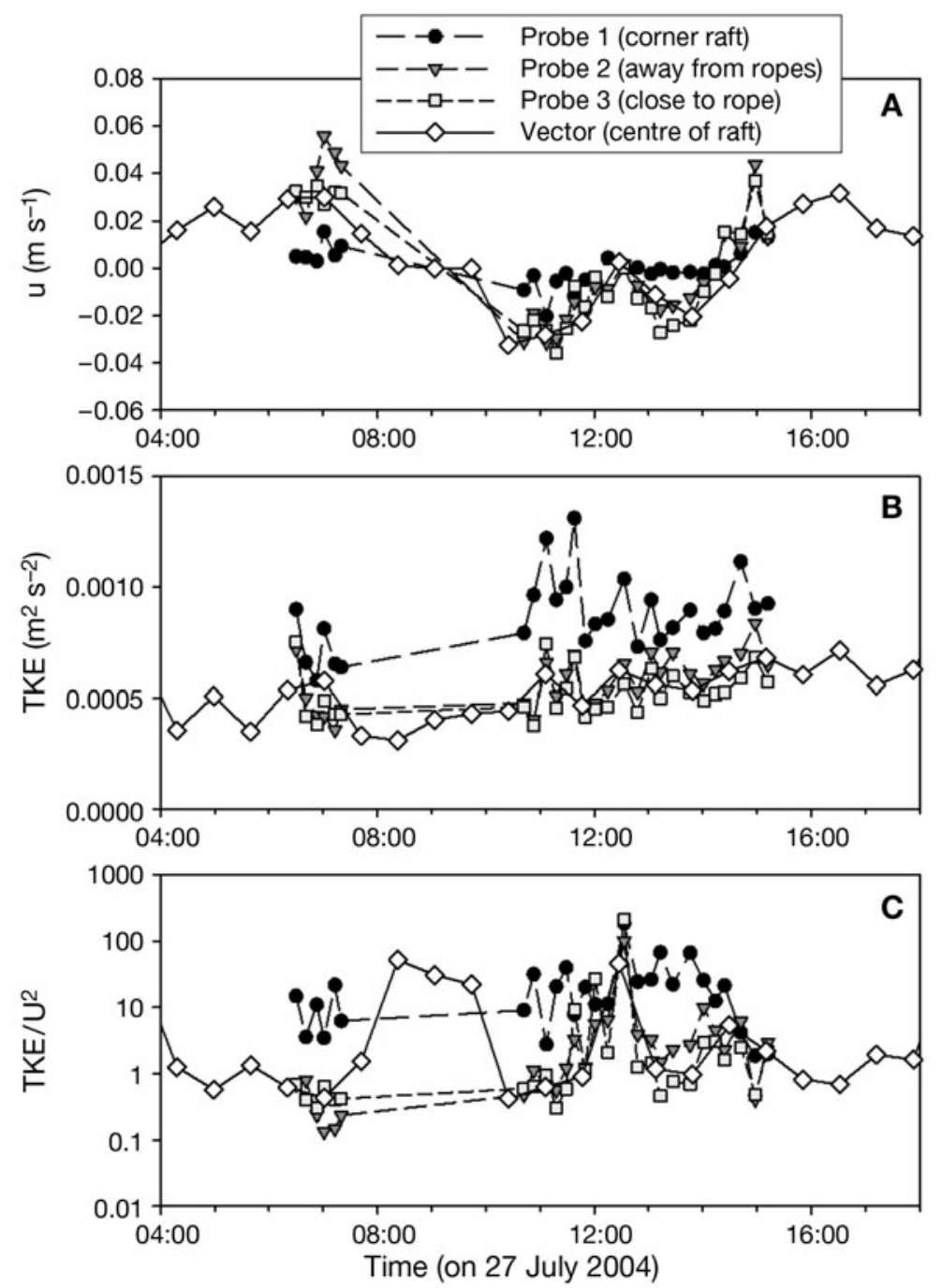

Fig. 4. (A) Velocities at 4 locations in the raft (only velocities along the main flow are shown). (B) Turbulent kinetic energy (TKE) at 4 locations in the raft. (C) Turbulence intensity, i.e. TKE normalised with the square of the velocity magnitude $\left(\mathrm{U}^{2}\right)$, at 4 locations in the raft. For clarity, only data for $1 \mathrm{~d}$ are shown. Data for other dates are consistent with these 
whether the measurements around this particular corner can directly be extrapolated to the 3 other raft corners. This will largely depend of the flow pattern outside the raft, and is therefore influenced by the phase of the tide and wake formation behind other rafts situated upstream.
Table 1. Paired $t$-tests comparing mean fluorescence ( 0 to $13 \mathrm{~m}$ ) between different stations from upstream to downstream of the raft for the study period. Significant difference for the study period is indicated by an asterisk $(\mathrm{p}<0.05)$

\begin{tabular}{|lccccccccc|} 
& \multicolumn{2}{c}{$\begin{array}{c}\text { Leading edge } \\
\text { df }\end{array}$} & \multicolumn{2}{c}{ Middle } & \multicolumn{2}{c|}{ Trailing edge } & \multicolumn{2}{c|}{ Downstream } \\
& & $\mathrm{d}$ & $\mathrm{df}$ & $\mathrm{p}$ & $\mathrm{df}$ & $\mathrm{p}$ & $\mathrm{df}$ & $\mathrm{p}$ \\
\hline Upstream & 6 & 0.10 & 10 & $0.010^{*}$ & 9 & $0.013^{*}$ & 10 & $0.006^{*}$ \\
Leading edge & & & 7 & $0.029^{*}$ & 6 & $0.031^{*}$ & 6 & 0.09 \\
Middle & & & & & 10 & 0.76 & 10 & 0.16 \\
Trailing edge & & & & & & & 9 & 0.14 \\
\hline
\end{tabular}

\section{Macro-scale depletion}

From the CTD casts different patterns of phytoplankton depletion emerged. On the macro-scale, there was a significant (paired $t$-test, df $=10, \mathrm{p}<0.05$ ) depletion of phytoplankton levels of fluorescence in the middle of the raft, in comparison with the reference station located 20 to $30 \mathrm{~m}$ upstream the raft (Fig. 5). This applies for the entire vertical extension of the long-lines (average $82 \pm$ $7 \%$ ), as well as in the 3 different layers that could be identified within the rope area from the density profiles. There was no significant difference between stations in the water column below the long-lines (15 to $19 \mathrm{~m}$ ), except on a few occasions, and no consistency was found in the pattern between days. Depletion in the middle of the raft ranged between 55 and $90 \%$ of the reference concentration depending on depth and sampling day. There was no significant correlation (Pearson; $\mathrm{n}=10, \mathrm{p}=$ 0.47 ) between current speed in the upper layer in the centre of the raft, measured as an average during and $0.5 \mathrm{~h}$ before water sampling, and depletion of phytoplankton, measured as fluorescence.

\section{Meso-scale depletion}

At meso-scale, comparing within and just around the raft, depletion of phytoplankton could be detected at 0

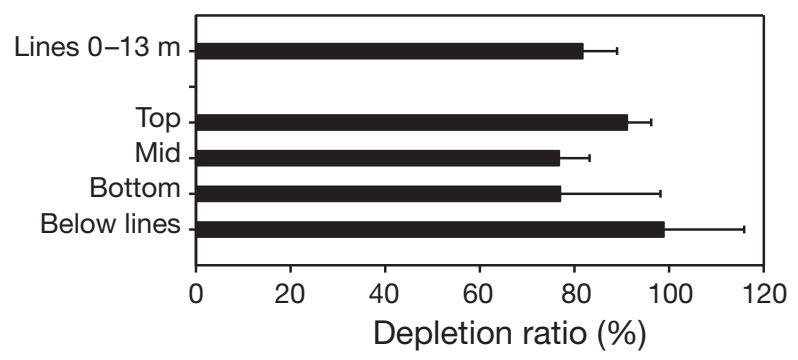

Fig. 5. Mean $( \pm \mathrm{SE})$ depletion ratios based on fluorescence measurements during the study period (12 sampling occasions) in the middle of the raft and at a reference station (100\%) outside the raft area upstream (see Fig. 2). Mean fluorescence was calculated for the part of the water column occupied by long-lines (0 to $13 \mathrm{~m}$ ), the 3 identified water column layers (top, mid and bottom) in the upper $13 \mathrm{~m}$ and below the long-lines (15 to $19 \mathrm{~m}$ ) to $13 \mathrm{~m}$ depth along the central part of the axis at 5 stations from upstream to downstream of the raft, whereas fluorescence increased along the central axis below the raft (Fig. 6). When comparing mean fluorescence (0 to $13 \mathrm{~m}$ ) for all days, there was always a significant depletion from upstream to the middle and further downstream of the raft (Table 1). In contrast, there was no significant depletion from upstream to the leading edge of the raft and from the middle and further downstream. Below the long-lines, there was no significant difference between stations (ANOVA, df $=9$, $\mathrm{p}=0.52$ )

On the $2 \mathrm{~d}$ where intensive CTD casts (extra CTD stations, Fig. 2) were performed, the most pronounced depletion gradient was observed along the central raft axis in the main current direction, while there was a weaker trend perpendicular to the central axis (Fig. 7). For all stations on both sampling days significant differences in fluorescence occurred between the upstream station and all other stations, except for the downstream and upstream edge stations on 22 July (ANOVA followed by Fisher's protected least significant difference post hoc test, $\mathrm{p}<0.05)$. On 22 July, water was outgoing and had low concentrations of

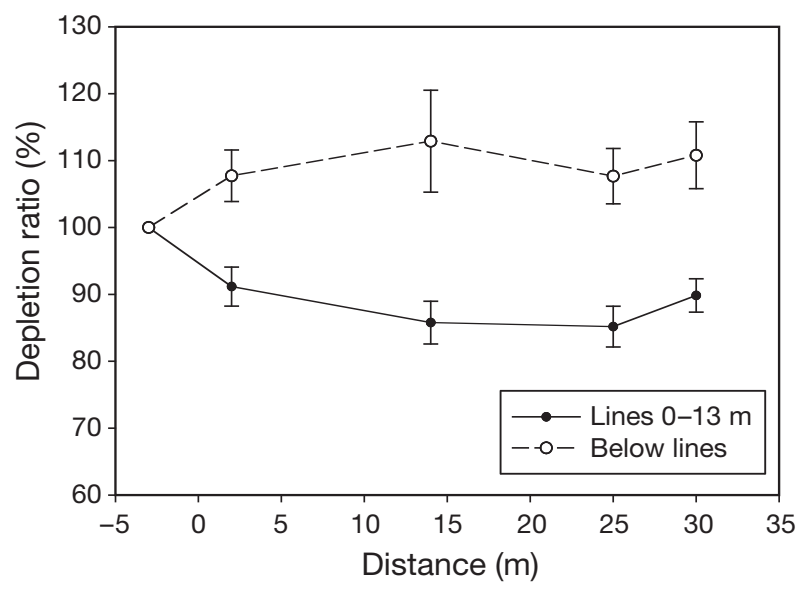

Fig. 6. Horizontal depletion of phytoplankton along the central axis measured from upstream $(-3 \mathrm{~m})$, at the leading edge $(2 \mathrm{~m})$, in the middle $(13.5 \mathrm{~m})$, at the trailing edge $(25 \mathrm{~m})$ and downstream $(30 \mathrm{~m})$ of the raft, shown for the full extension of long-lines ( 0 to $13 \mathrm{~m}$ ) and below the long-lines (15 to $19 \mathrm{~m})$. The raft length extends from 0 to $27 \mathrm{~m}$. Values are mean $\pm \mathrm{SD}$ 


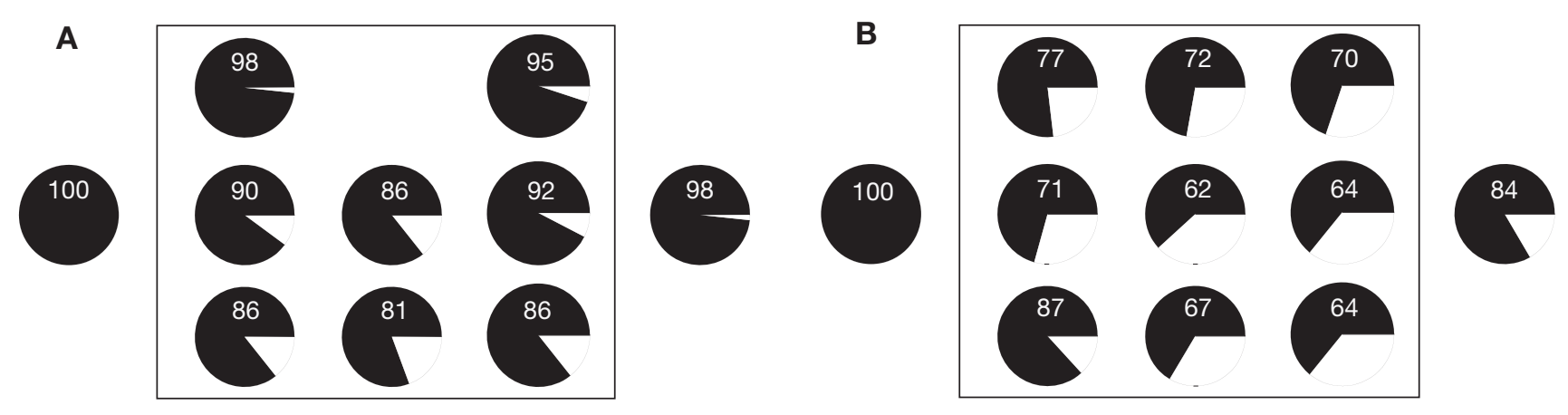

Fig. 7. Mean depletion of fluorescence upstream (100\%), at 9 stations within the raft area, and downstream of the raft on (A) 22 July and (B) 28 July. Depletion is calculated as a mean of the part of the water column occupied by mussels (0 to $13 \mathrm{~m})$. The positions of the stations within and outside the raft are shown in Fig. 2. One sampling point in (A) is missing due to loss of data during data transmission

chl $a_{\text {; }}$ on 28 July, the water was incoming and the concentrations of chl a were higher.

Upstream concentrations of chl a at 3 and $9 \mathrm{~m}$ depth varied from 0.5 to $4.4 \mathrm{mg} \mathrm{m}^{-3}$ and were in general lower than the values at $18 \mathrm{~m}$ depth, except on 27 July (Fig. 8). The $>2 \mu \mathrm{m}$ size fraction available to mussels contributed on average $( \pm$ SD) $72 \pm 13 \%$ of total chl a. On 27 July, at an ingoing tide, the downstream depletion was masked, because water sampling accidentally overlapped slack water in the tidal cycle. These values are, thus, not included in calculations of depletion. There was significant depletion of chl $a$ in the size fractions 2 to 20 and $>20 \mu \mathrm{m}$ in the middle, at the trailing edge and downstream of the raft at 3 and $9 \mathrm{~m}$ depth compared to upstream concentrations (Fig. 9, Table 2). Depletion of chl a $>2 \mu \mathrm{m}$ was not correlated to current speed (Pearson; $\mathrm{n}=5, \mathrm{p}=0.63$ ). There were no significant differences in phytoplankton concentrations for any size fraction of chl a below the long-lines $(18 \mathrm{~m})$ or for the size fraction $<2 \mu \mathrm{m}$ at any depth. Total chl a concentrations were lower in the studied farm area and in the canal with mussel farms than in the open Guia without mussel farms (data not shown).

\section{Micro-scale depletion}

On the micro-scale (around and inside the mussel clumps) a gradient towards the mussel rope was found when sampling in the middle of the raft (Fig. 10A). Depletion ratios close to the mussel rope were on average $( \pm \mathrm{SE}) 63 \pm 2 \%$ and $74 \pm 15 \%$ at 3 and $9 \mathrm{~m}$ depths, respectively, of concentrations between ropes $(0.20 \mathrm{~m}$ from rope). In general, depletion ratios were similar at all depths and sampling occasions, except on 27 July $(9 \mathrm{~m})$, when depletion was very high $(18 \%)$. Depletion rates calculated as the slope of the linear regression between the concentration of chl a (dependent variable) and the distance, on a log-scale, from the mussel rope (independent variable) varied between 0.03 and 0.39 . In contrast, depletion ratios measured at the corner of the raft were less consistent between depths and sampling occasions (Fig. 10B). Depletion close to the rope ranged from 45 to $136 \%$ of concentrations between ropes, and a clear gradient towards the mussel rope could not always be detected. No significant gradients were found on 1 occasion at $3 \mathrm{~m}$ and 3 occasions at $9 \mathrm{~m}$; for the remaining sampling occasions, significant depletion was found, with depletion rates ranging from 0.03 to 0.12 and $r^{2}$ ranging from 0.50 to 0.99 .

The chlorophyll values derived from the 'signal-tonoise-ratio' data from the ADV measurements support the data on the meso- and micro-scales (Fig. 11). There was a clear difference in particle concentration in measurements from the centre of the raft ('Vector') compared to measurements between ropes (Probe 2). The reduction in derived chlorophyll concentration amounted to about $20 \%$. Similarly, concentrations were lower close to a mussel rope (Probe 3 ) compared to between ropes at similar positions in the raft. Despite the close proximity to the edge of the raft, derived chlorophyll concentrations were consistently relatively low at the corner of the raft (Probe 1). These derived values were generally of the same order of magnitude as the derived values at the centre of the raft. This appears to confirm the presence of more or less stagnant volumes of water at this corner of the raft.

\section{Depletion model}

The mean individual clearance rate (CR) in the study period estimated from Eq. (3) was $0.61 \mathrm{~h}^{-1}$ ind..$^{-1}$ based on fluorescence depletion in the upper mixed layer and $0.9 \mathrm{l} \mathrm{h}^{-1}$ ind. $^{-1}$ if using mean fluorescence for the entire extension of the mussel ropes. The corresponding CR calculated using concentrations of chl a of phytoplankton $>2 \mu \mathrm{m}$ are, respectively, 2.4 and $2.9 \mathrm{l}$ $\mathrm{h}^{-1}$ ind. $^{-1}$. Ingestion rates were 2.3 and $3.2 \mathrm{mg} \mathrm{C} \mathrm{d}^{-1}$ ind. ${ }^{-1}$, calculated, respectively, for the upper layer and the entire extension of the mussel ropes. 

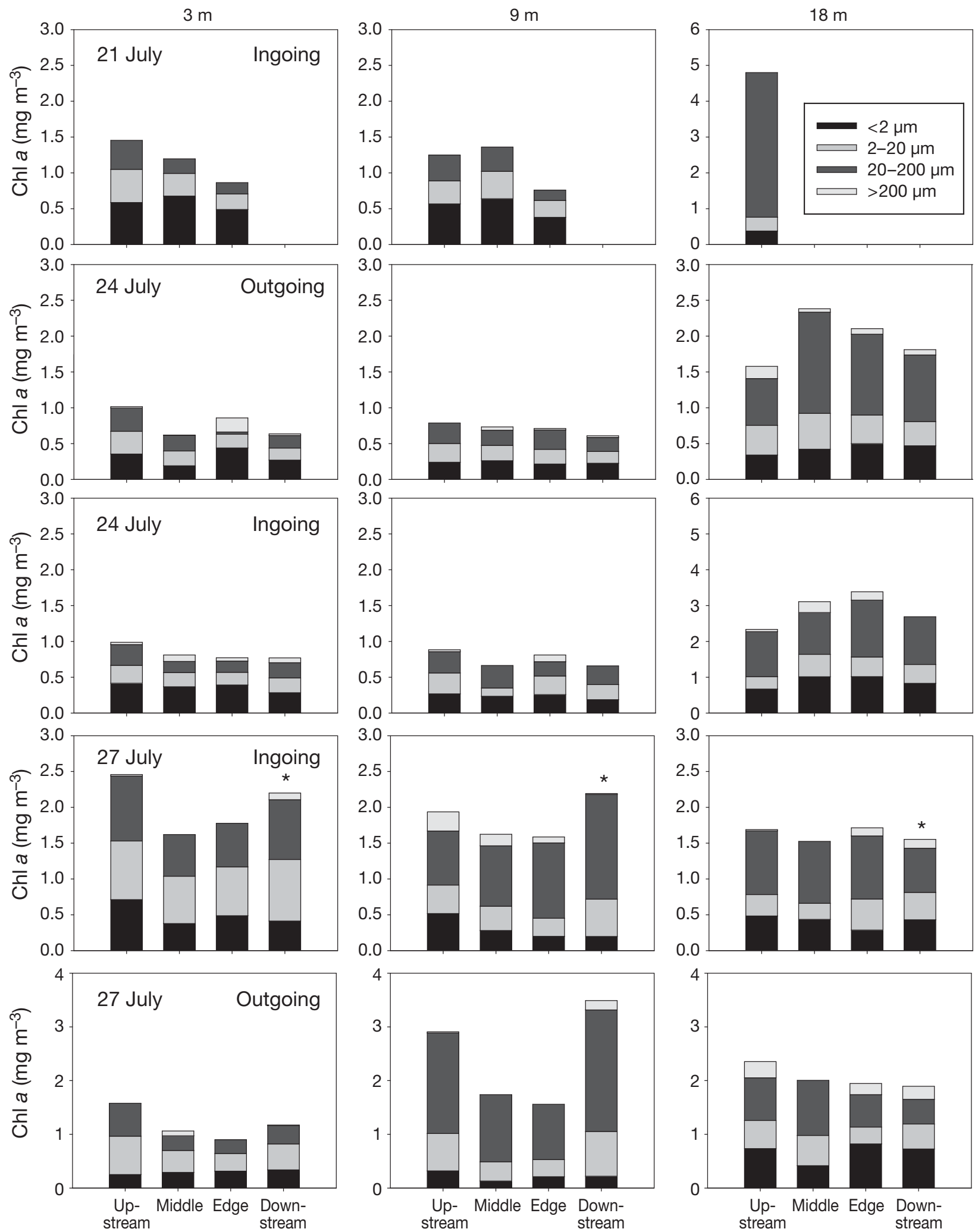

Position on raft

Fig. 8. Concentrations of size-fractionated chl a $\left(\mathrm{mg} \mathrm{m}^{-3}\right)$ at 3, 9 and $18 \mathrm{~m}$ depth upstream, in the middle, at the edge, and downstream of the raft on 5 sampling occasions. Data marked with an asterisk are not included in calculated average depletion rate. 

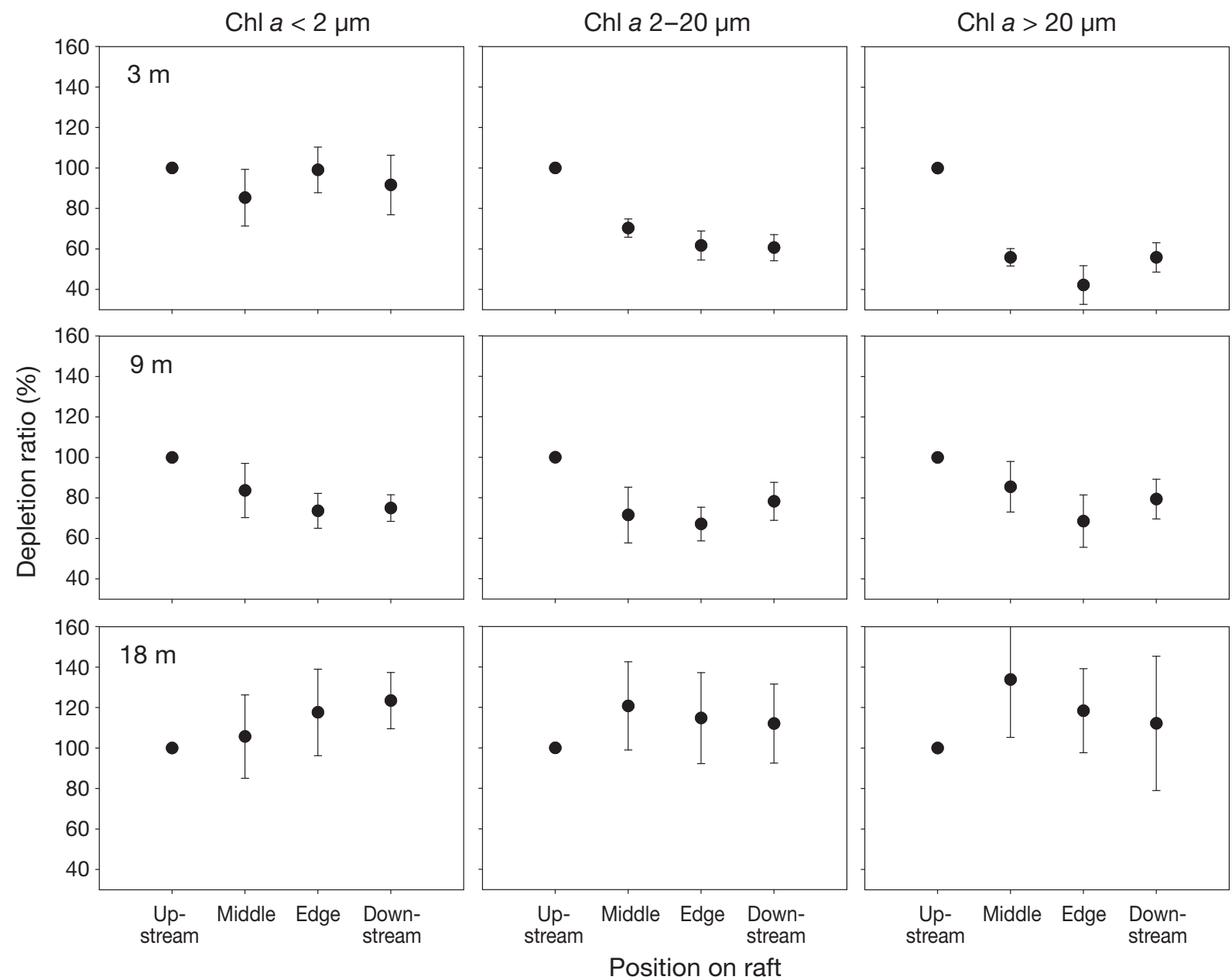

Fig. 9. Average depletion ratio of size-fractionated chl a across the raft for all sampling days. Values are mean \pm SD

\section{DISCUSSION}

In the present study, we observed a clear depletion in phytoplankton as the water masses passed through a mussel cultivation unit, in agreement with our hypothesis. Depletion was detected on different spatial scales, under different hydrodynamic regimes and phytoplankton concentrations, and using different methods; i.e. water samples, fluorescence measurements and

Table 2. One-sample $t$-tests of depletion ratios of size-fractionated chlorophyll a ( $\mathrm{chl}$ a) at the middle, trailing edge and downstream stations, testing whether they are significantly different $\left({ }^{*}\right)$ from the upstream value of $1(p<0.05)$

\begin{tabular}{|llllllll|}
\hline & \multicolumn{3}{c}{ Middle } & \multicolumn{2}{c|}{ Trailing edge } & \multicolumn{2}{c|}{ Downstream } \\
& \multicolumn{1}{c}{$\mathrm{p}$} & $\mathrm{df}$ & $\mathrm{p}$ & $\mathrm{df}$ & $\mathrm{p}$ & $\mathrm{df}$ \\
\hline $\mathrm{Chl} a<2 \mu \mathrm{m}(3$ and $9 \mathrm{~m})$ & 0.056 & 9 & 0.496 & 9 & 0.074 & 7 \\
Chl $a 2-20 \mu \mathrm{m}(3$ and $9 \mathrm{~m})$ & $0.002^{*}$ & 9 & $0.001^{*}$ & 9 & $0.002^{*}$ & 7 \\
Chl $a>20 \mu \mathrm{m}(3$ and $9 \mathrm{~m})$ & $0.002^{*}$ & 9 & $0.001^{*}$ & 9 & $0.001^{*}$ & 7 \\
Chl $a<2$ and $>2 \mu \mathrm{m}(18 \mathrm{~m})$ & 0.249 & 7 & 0.218 & 7 & 0.170 & 5 \\
\hline
\end{tabular}

ADV backscatter. In general, there was consistency between estimates of depletion; inside the raft, chl a concentrations were on average $\sim 60$ to $80 \%$ of the reference concentrations. Levels of depletion in the present study are in accordance with previously reported levels of phytoplankton reduction of $\sim 30 \%$ from mussel rafts in Spanish rías (Perez Camacho et al. 1991), although these were estimated, rather than measured, reductions. In comparison, measured levels of depletion in other areas range from no depletion or enhancement of food levels (Ogilvie et al. 2000) to depletion of $30 \%$ of upstream concentration (Strohmeier et al. 2005), depending on stocking density (Heasman et al. 1998) and size/orientation of the cultivation unit (Strohmeier et al. 2005). However, depletion was most significant in the centre of the unit and not, as hypothesised, at the downstream end. This might be caused by intrusion at the downstream end created by 


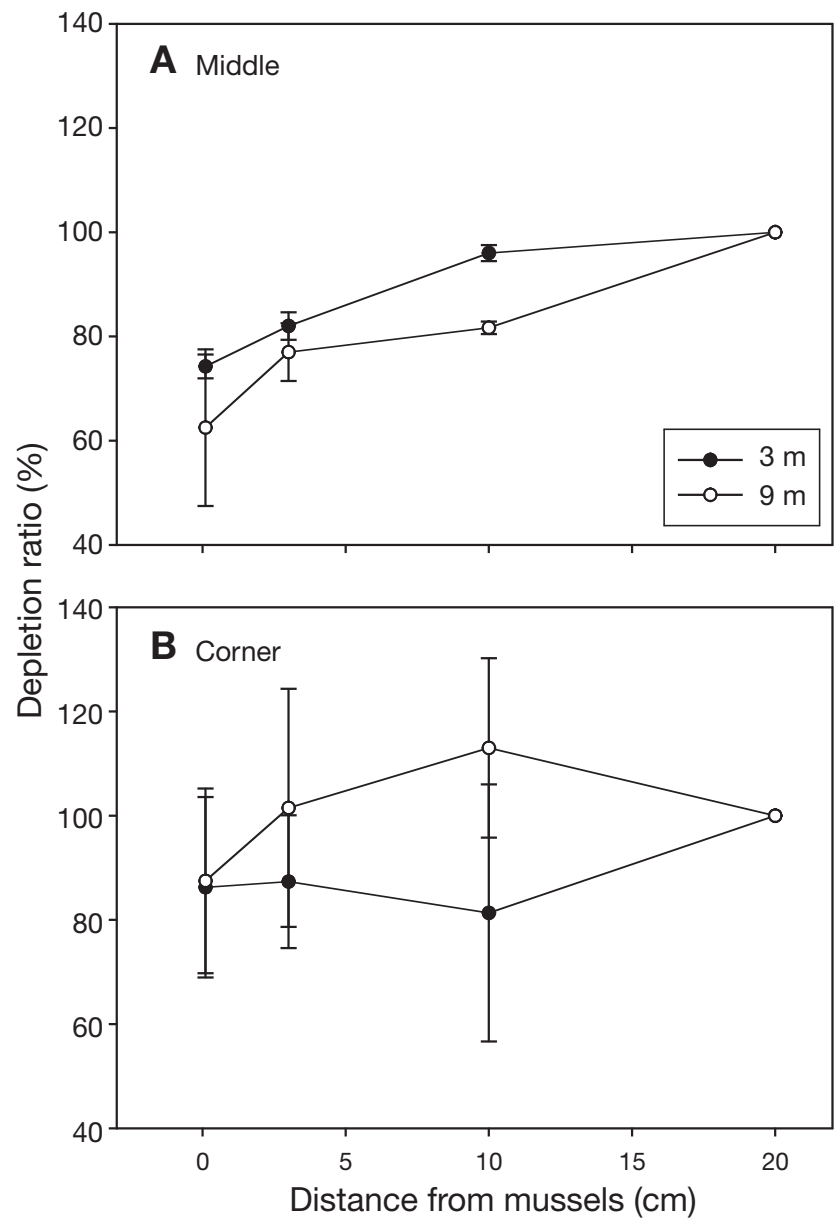

Fig. 10. Mean $( \pm \mathrm{SE})$ depletion ratios with distance from a mussel long-line sampled at 2 depths ( 3 and $9 \mathrm{~m}$ ) based on chl a measurements by siphon mimics vortices generated behind the raft (Riethmüller et al. 2006) of less depleted or non-depleted water from the sides and below.

On a micro-scale, we used a novel technique sampling undisturbed water and demonstrating depletion close to mussel ropes. This is the food level that mussels actually experience within a raft and that determine their growth. As seen from the present study, the micro-scale measurements may reveal surprising details, such as the low levels of food at the upstream corners of the raft. The depletion on a centimetre scale can be implemented into models of depletion on a raft scale as either a reduction of food levels with a fraction of the between rope concentration at a given position or as a reduced filtration rate. Failing to account for micro-scale depletion will overestimate actual food availability to mussels in model calculations.

Since phytoplankton concentrations were mostly depleted at the centre of the raft, it is supposedly most profitable for a mussel to be placed at the edges of a cultivation unit in a tidal system such as the Ría de Vigo. However, due to a larger scale flow phenomenon around the raft, at least 1 corner also proved to be an unexpectedly unfavourable position. The stationary vortices around the corner provided a lot of very local turbulence, but, on a slightly larger scale, there was little exchange of water-and thus phytoplankton-with the water masses passing by. The high levels of turbulence at the corner resulted in less clear concentration profiles on a micro-scale, but also in lower overall concentrations of chl $a$ at the corner. This was particularly clear from the ADV measurements. Turbulent eddies around the perimeter of cultivation units have previously been described (Boyd \& Heasman 1998), but may, in more open cultivation structures, facilitate intrusion of water into the unit at the edges. Creation of eddies and their exact nature will depend, not only on current regime, but also on physical properties, i.e. shape, dimensions and density of ropes, design and orientation of the cultivation unit, and density and spacing of the array of cultivation units.

A raft can be considered to be an obstacle that causes the approaching water to diverge to the sides and beneath it and, thus, to reduce flow considerably inside the raft, among the ropes. Diversion of flow has also been observed in both the investigated raft (R. Riethmüller pers. comm.) and in other raft cultures (Boyd \& Heasman 1998). However, a clear tidal signal could be detected inside the raft, and peak velocities in the middle of the
Fig. 11. Chl a concentrations estimated from ADV backscatter at different positions on the raft on 27 July 2004. For clarity, only data for $1 \mathrm{~d}$ are shown. Data for other dates are consistent with these 
raft were around $50 \%$ of the peak velocities outside the raft (R. Riethmüller pers. comm.). Average velocities were around 20 to $30 \%$ of outside velocities; these values are slightly higher than previously measured inside both raft cultures (Boyd \& Heasman 1998) and long-line units (Strohmeier et al. 2005, Aure et al. 2007). The fact that there is significant flow within the raft is almost certainly due to 2 factors: (1) alignment of the raft in the flow allows channelling of the flow and (2) fairly slow flow reduces strong wake formation behind the mussel ropes. In a higher flow area, the relative flow reduction can be expected to be much higher, due to the much higher form drag and interaction of the wakes behind the ropes. This implies that a higher flow velocity in the area may not automatically lead to higher levels of mussel production or that maximum rope density can be much higher. A wake or dead zone was observed downstream of the raft (Riethmüller et al. 2006), but it was of a small extension (30 to $50 \mathrm{~m}$ ), as also seen from the fast recovery of upstream chl a levels in the present study. With a wake of 30 to $50 \mathrm{~m}$, the $100 \mathrm{~m}$ distance between rafts in the polygon may thus represent an optimum distance for renewal of food supply in relation to the demand for optimal area use. Even though intrusion of water from below and from the sides may lead to renewed food supply, assemblage of rafts in polygons can be expected to lead to an overall depletion affecting production in individual rafts (Riethmüller et al. 2006), which can also be seen from the general lower phytoplankton concentrations at ebb tide compared to flood tide. There are, however, to our knowledge, no published data demonstrating differences in production in relation to polygon size or raft position within polygons.

In the meso-scale comparison from just upstream to inside the raft there were some differences in results both between methods and over time. Estimates of depletion were higher (lower levels of phytoplankton in the middle of the raft) using size-fractionated chl a from water samples compared to fluorescence measurements. The obvious explanation for this discrepancy is the fact that Mytilus sp. have reduced retention efficiency for particles <4 um (Jørgensen 1990). The fluorescence measurements encompassed all size fractions of phytoplankton, whereas the water samples could distinguish the ingestible fraction from the fraction that was too small to be retained by the mussels. Since almost $30 \%$ of the phytoplankton was $<2 \mu \mathrm{m}$, and there was no significant depletion of this size fraction, the size-selective retention of mussels can explain the entire difference between the 2 methods. This result implies for measurements of depletion that one cannot entirely rely on automatic equipment. In terms of potential food sources, the picophytoplankton $(<2 \mu \mathrm{m})$ fraction has been measured to have a C:chl $a$ ratio of 76 during summer stratification, the small nanophytoplankton fraction ( 2 to $5 \mu \mathrm{m}$ ) had a ratio of 44, whereas larger, $100 \%$ efficiently retained fractions had ratios from 33 to 97 (Cermeño et al. 2006). The food supply to mussels can thus roughly be assumed to be reflected in the available chl a concentrations.

In contrast to our hypothesis, we could not detect any effect of current speed on depletion, which can probably be attributed to little variance in current speed inside the raft $\left(0.015\right.$ to $\left.0.04 \mathrm{~m} \mathrm{~s}^{-1}\right)$. Furthermore, the (in general) low phytoplankton concentrations, occasionally $<0.6 \mu \mathrm{g} \mathrm{l}^{-1}$, may have reduced the mussel filtration rate (Riisgård et al. 2003) and thus the level of depletion on specific days. This may also be the reason for the difference in depletion rates within the raft (meso-scale) on 2 different sampling occasions. In general, water is depleted of phytoplankton on the falling tide by outgoing water, and the very low concentrations of chl a were recorded for outgoing water. A low level of phytoplankton is not the normal situation for the Ría de Vigo. This was undoubtedly a consequence of the prolonged relaxation of the normal upwelling condition that was characteristic of this area at the time of the study.

The limited number of reported measurements on food depletion within mussel cultivation units has almost uniformly shown food depletion in the middle or at the downstream ends of the unit, irrespective of whether raft cultures (Heasman et al. 1998) or longline units (Strohmeier et al. 2005) have been studied. The implication in a tidal system such as the Ría de Vigo is that mussels in the middle of a raft should grow less than mussels at the perimeter. Mussel farmers in the area have, for the same reason, a culture practice, whereby the positions of individual ropes are changed during the growing phase. Such a practice will need to be advanced if local authorities are to meet the farmer's wishes for larger rafts. Interestingly, there is no firm evidence in terms of growth studies confirming slower or less growth in the middle of cultivation units. In a Galician raft using only 1 anchor, i.e. with permanent upstream and downstream ends, 1 study showed clear differences in growth between the positions (Fuentes \& Molares 1994), whereas the result was less clear in a later study from the same area (Fuentes et al. 2000). Using the condition index as a proxy for growth, Heasman et al. (1998) detected, in a similar type of raft culture unit, reduced growth in the middle of the raft, but, in some cases, no clear differences in growth between different positions in the raft were found. Density of mussels, and thus competition for food, is important for growth (Heasman et al. 1998, Fuentes et al. 2000) and may explain why some units experience horizontal variation in growth/production. Density will affect the level of re-filtration, and dense cultures 
with little distance between ropes may also affect flow fields and water transport through the unit.

Using the advection depletion model, realised clearance rates could be estimated to be a maximum of $2.9 \mathrm{l}$ $\mathrm{h}^{-1}$ ind..$^{-1}$, which is 60 to $90 \%$ of the potential clearance rates for mussels of an average size of $40 \mathrm{~mm}$ at 15 to $20^{\circ} \mathrm{C}$ (Riisgård 2001, Petersen et al. 2004). Reduced realised clearance rates compared to maximum clearance under controlled conditions in the laboratory may be due to re-filtration of water, as seen at the corner of the raft (Wildish \& Kristmanson 1997) and, occasionally, very low concentrations of chl $a$ in the water (Riisgård et al. 2003). Taking these conditions into consideration, the estimated clearance rates are in good agreement with measured depletion. From the measured concentrations of ingestible phytoplankton carbon, growth rates of $<0.6 \mathrm{~d}^{-1}$ can be estimated for the study period (Maar et al. 2008), which is far below previous recorded growth rates (Navarro et al. 1991). The study period was, however, characterised by a relaxation period and unusually low phytoplankton concentrations for the time of the year (Arbones et al. 2008) and these growth rates cannot be considered typical.

In summary, depletion of food was documented on different scales, and surprisingly this was not only found in the centre of the raft, but also around upstream corners. Further, depletion was most significant in the centre of the unit and not, as expected, at the downstream end. The raft acted as an obstacle, and there are indications of flow deflection, but significant flow passed through the raft, probably due to its orientation and geometry. Functional depletion was dependent on current velocity and size of the phytoplankton, and our study shows that it is important to include the picoplankton fraction in the measurements in order to estimate both the effect of mussel grazing on phytoplankton biomass and composition and food availability to mussels. We recommend that mussel farmers perform model studies before raft production is increased by increasing raft size, in order to avoid more serious food depletion.

Acknowledgements. This study was supported by the MaBenE-grant (EKV3-2001-00144) and the Danish National Research Council (Grant 21-04-0391). We thank J. Larsen and B. Søborg for technical assistance during the field work and the crew on 'Mytilus'. Furthermore, we are indebted to Peter Hendricks (Newport Naval Lab, USA) for allowing us to deploy his 3 coupled Sontek ADV probes without any cost.

\section{LITERATURE CITED}

Arbones B, Castro CG, Alonso-Pérez F, Figueras FG (2008) Phytoplankton size structure and water column metabolic balance in a coastal upwelling system: the Ría de Vigo, NW Iberia. Aquat Microb Ecol 50:169-179
Aure J, Strohmeier T, Strand Ø (2007) Modelling current speed and carrying capacity in long-line blue mussel (Mytilus edulis) farms. Aquacult Res 38:304-312

Babarro JMF, Fernandez RMJ, Labarta U (2000) Growth of seed mussel (Mytilus galloprovincialis Lmk): effects of environmental parameters and seed origin. J Shellfish Res 19:187-193

Bacher C, Grant J, Hawkins AJS, Fang J, Zhu M, Besnard M (2003) Modelling the effect of food depletion on scallop growth in Sungo Bay (China). Aquat Living Resour 16: $10-24$

Boyd AJ, Heasman KG (1998) Shellfish mariculture in the Benguela system: water flow patterns within a mussel farm in Saldanha Bay, South Africa. J Shellfish Res 17: $25-32$

> Cermeño P, Marañón E, Pérez V, Serret P, Fernández E, Castro CG (2006) Phytoplankton size structure and primary production in a highly dynamic coastal ecosystem (Ría de Vigo, NW Spain): seasonal and short-time scale variability. Estuar Coast Shelf Sci 67:251-266

> Fuentes J, Molares J (1994) Settlement of the mussel Mytilus galloprovincialis on collectors suspended from rafts in the Ria de Arousa (NW of Spain): annual pattern and spatial variability. Aquaculture 122:55-62

> Fuentes J, Gregorio V, Giraldez R, Molares J (2000) Withinraft variability of the growth rate of mussels, Mytilus galloprovincialis, cultivated in the Ria de Arousa (NW Spain). Aquaculture 189:39-52

Gibbs MT (2004) Interactions between bivalve shellfish farms and fishery resources. Aquaculture 240:267-296

Heasman KG, Pitcher GC, McQuaid CD, Hecht T (1998) Shellfish mariculture in the Benguela system: raft culture of Mytilus galloprovincialis and the effect of rope spacing on food extraction, growth rate, production, and condition of mussels. J Shellfish Res 17:33-39

Jørgensen CB (1990) Bivalve filter feeding: hydrodynamics, bioenergetics, physiology and ecology. Olsen \& Olsen, Fredensborg

Maar M, Nielsen TG, Petersen JK (2008) Depletion of plankton in a raft culture of Mytilus galloprovincialis in Ría de Vigo, NW Spain. II. Zooplankton. Aquat Biol 4:127-141

Navarro E, Iglesias JP, Camacho AP, Labarta U, Beiras R (1991) The physiological energetics of mussels (Mytilus galloprovincialis Lmk) from different cultivation rafts in the Ria de Arosa (Galicia, NW Spain). Aquaculture 94: $197-212$

> Ogilvie SC, Ross AH, Schiel DR (2000) Phytoplankton biomass associated with mussel farms in Beatrix Bay, New Zealand. Aquaculture 181:71-80

> Perez Camacho A, Gonzalez R, Fuentes J (1991) Mussel culture in Galicia (N.W. Spain). Aquaculture 94:263-278

Petersen JK (2004) Grazing on pelagic primary producersthe role of benthic suspension feeders in estuaries. In: Nielsen SL, Banta GT, Pedersen MF (eds) Estuarine nutrient cycling: the influence of primary producers. Kluwer Academic Publishers, Dordrecht, p 129-152

> Petersen JK, Bougrier S, Smaal A, Garen P, Robert S, Larsen JEN, Brummelhuis E (2004) Intercalibration of mussel Mytilus edulis clearance rate measurements. Mar Ecol Prog Ser 267:187-194

> Pilditch CA, Grant J, Bryan KR (2001) Seston supply to sea scallops (Placopecten magellanicus) in suspended culture. Can J Fish Aquat Sci 58:241-253

Riethmüller R, Jäger N, Häse C, Fernandes L, Neves R (2006) Flow patterns around and within a raft mussel farm in Ría de Vigo, Spain. Report No. D2.2b, GKSS, Hamburg

Riisgård HU, Kittner C, Seerup DF (2003) Regulation of open- 
ing state and filtration rate in filter-feeding bivalves (Cardium edule, Mytilus edulis, Mya arenaria) in response to low algal concentration. J Exp Mar Biol Ecol 284:105-127

- Riisgård HU (2001) On measurement of filtration rate in bivalves - the stony road to reliable data: review and interpretation. Mar Ecol Prog Ser 211:275-291

Smaal AC (2002) European mussel cultivation along the Atlantic coast: production status, problems and perspectives. Hydrobiologia 484:89-98

Strohmeier T, Aure J, Duinker A, Castberg T, Svardal A, Strand $\varnothing$ (2005) Flow reduction, seston depletion, meat

Editorial responsibility: Peter Beninger, Nantes, France content and distribution of diarrhetic shellfish toxins in a long-line blue mussel (Mytilus edulis) farm. J Shellfish Res 24:15-23

Voulgaris G, Meyers ST (2004) Temporal variability of hydrodynamics, sediment concentration and sediment settling velocity in a tidal creek. Cont Shelf Res 24:1659-1683

Wildish D, Kristmanson D (1997) Benthic suspension feeders and flow. Cambridge University Press, New York

Yentsch CS, Menzel DW (1963) A method for the determination of phytoplankton chlorophyll and phaeophytin by fluorescence. Deep Sea Res I Oceanogr Res Pap 10:221-231

Submitted: February 1, 2008; Accepted: September 9, 2008 Proofs received from author(s): October 8, 2008 